\title{
Lower and Higher Copies in Arabic
}

https://doi.org/10.33806/ijaes2000.19.1.5

\author{
Ayman Yasin
}

Princess Sumaya University for Technology, Jordan

\begin{abstract}
This paper examines the phenomenon of copying in Standard Arabic (SA) within the copy theory. Following Boskovic and Nunes (2007), the researcher contends that Arabic utilizes two ways for the pronunciation of heads and copies governed by syntactic and phonological constraints. The highest link can be phonetically realized, or copies are pronounced instead of their heads by PLC without causing the derivation to crash. The paper shows how the copy theory accounts for the differences between perfective and imperative forms on one hand and the imperfective form on the other hand. The copy theory helps account for $V$-to- $T^{0}$ movement in imperatives and perfectives in comparison with remaining in lower projections in imperfectives. Further, the research reveals that certain fixed word orders in Arabic can be accounted for in terms of the copy theory. The type of the object DP plays a role in which copy is realized, and hence affects word order. The higher copy of the object DP is pronounced when it is an enclitic object pronoun, while the lower copy is pronounced when the object is an $R$-expression DP. Addressing the topic of copying from a semantics-syntax interface perspective, the paper explains the bearings of copy operations on syntax.
\end{abstract}

Keywords: Arabic, copying, imperatives and perfectives, syntax

\section{Introduction}

The deletion of copies is determined by the linearization procedures that the grammar makes available (Hornstein, Nunes and Kleanthes 2010:18). However, if they are not deleted in the phonological component, they cause the derivation to crash at PF because they contradict linearization principles as some syntactic object may precede and be preceded by some other syntactic object. Nonetheless, "multiple copies can be pronounced if they are able to evade the conditions that force their deletion" (Hornstein et al. 2010: 247).

This paper provides evidence that in SA, the pronunciation of the higher or lower copy is governed by syntactic and phonological constraints. Standard Arabic may pronounce either the upper or lower copy. For instance, Jordanian Arabic moves the non-quntificational material in wh-phrases as in 01a). However, there are cases where that material is left behind as shown in 0 below $^{1}$ :
a. [gaddeif
sukkar $_{\mathrm{i}}$
ftar-eit
[ $t_{i}$ ]
how much
sugar
buy:PRF-2SM
b. gaddei $\int_{\mathrm{i}}$
ftar-eit
[ $\mathrm{t}_{\mathrm{i}}$ sukkar] 
how much buy:PRF-2SM sugar

'How much sugar did you buy?'

Moreover, the copy theory allows us to account for the fact that $\mathrm{V}$ moves to $\mathrm{T}^{0}$ in imperfective forms whereas it remains in lower projections in the case of imperatives and perfectives.

(1) a. faSal-at

$d o:$ PRF:3SF-SUBJ

'She did.'

b. ta-fYal-u

IMPF:3SF-do-IND

'She does/ she is doing.'

The PERSON feature is copied in the head of the chain in imperfectives and in the foot of the chain in imperatives and perfectives as we will discuss in section 3.2 .

The above-mentioned examples will be discussed within the theoretical framework of the copy theory (Chomsky 1995; Boskovic and Nunes 2007; Haegeman 2009; Radford 2009; Hornstein et al. 2010).

This paper proceeds as follows: section 2 presents a background on the copy theory. Section 3 addresses the pronunciation of the head or the foot of a chain through discussing imperatives, perfectives and imperfectives, and enclitic object pronouns. Section 4 concludes.

\section{Background}

Sentences are derived by means of two operations, Merge and Move, where Merge assembles a structure of hierarchically organized constituents and Move displaces a constituent from the position in which it has been merged and merges it in some higher position in the structure (Chomsky 1993, 1995 and Hornstein et al. 2010:240,278,337). Haegeman (2009:320) states that "Moved constituents leave a copy... to ensure that the relations they have with various constituents in the sentence can remain encoded".

(3) a. What exactly do you mean?

b. What do you mean exactly?

(3a) is analyzed as a leftward movement: the wh-constituent what exactly is displaced from the complement position of the verb mean to the specifier position of CP. This, in turn, proves that what exactly is a constituent.

c. [CP What exactly [C, [C do] [тP you [PRNT][ve you mean what exactly ]]]]?

By contrast, the alternative question in (3b) has been formulated by a discontinuous constituent what ...exactly. In other words, the object NP of mean is split up: only what moved to [spec/CP]. Since (3a) and (3b) are semantically related, we assume that the moved interrogative pronoun what and the adverb exactly are first merged as one constituent and then movement of what leaves the adverb exactly stranded:

d. [CP What [C, [C do] [Tr you [PRNT] [VP you mean whatexactly]]]]?

In language acquisition, young children sometimes produce auxiliary copying structures as the following example: 

a. Can its wheels can spin?
b. Did the kitchen light did flash?
c. Is the steam is hot?

As Radford (2009:149) explains, Sam, the child who produced these sentences, is merging can, did and is in C, but he hasn't mastered the copydeletion component of auxiliary inversion and therefore he fails to delete the phonetic features of the original occurrence of AUX in T. This example suggests that movement operations like auxiliary-inversion can best be analyzed as a composite operation of copy-merge and copy-deletion.

Chomsky (1993) maintains that a moved constituent leaves behind a copy of itself when it moves, with the copy generally having its phonetic features deleted. He further demonstrates that the copy theory considerably simplifies the analysis of reconstruction phenomena by making it possible to treat reconstruction as an LF phenomenon and that only one copy of X remains at the interface levels.

Boskovic and Nunes (2007:1) argue that convergence requirements related to linearization and morphological fusion interact with economy computations regarding applications of deletion, yielding a complex cross-linguistic pattern. Whereby chains in the general case have only their highest link phonetically realized because higher copies usually have more checking relations whereas lower copies bear more unchecked features. Therefore, the deletion of higher copies requires additional applications of FF-Elimination in order for the derivation to converge. By comparison, lower copies bear more unchecked features that would lead the derivation to a crash. Deleting these copies along with their features is more economical than deleting the higher copy and additionally deleting the unchecked features of the lower copies (Nunes 2004).

At $\mathrm{PF}$ there is a choice concerning which member of a chain survives deletion (Bobaljik 1995, 2002; Brody 1995; Nunes 1995, 2004; Pesetsky 1997, 1998; Roberts 1997; Franks 1998; Hiramatsu 2000; Lambova 2002, 2004; Miyoshi 2002; Landau 2003; Runner 2013 among others). Franks (1998) argues that a chain is pronounced in the head position, with lower members deleted at PF, unless the pronunciation in the head position would lead to a PF violation. If and only if the violation can be avoided by pronouncing a lower member of the chain, the lower member is pronounced and the head of the chain is deleted. Boskovic and Nunes (2007) refer to the mechanism of pronunciation of lower copies motivated by PF considerations as Pronounce Lower Copy (PLC). PLC will mainly be discussed in imperatives and perfectives.

Applying the Copy-plus-Merge Theory of Movement (Nunes 2004) to Standard Arabic, Haddad (2012) discusses three types of "raising" constructions in Standard Arabic: forward raising, where a higher copy of the subject appears in the matrix clause since it merges in the subordinate clause before moving to the matrix clause where it is pronounced; backward raising, where the lower copy of a subject is spelled-out in the embedded clause since the subject moves to the matrix clause and shows agreement with the matrix predicate, however, it is 
spelled-out in the subordinate clause; and non-raising structure where the subject surfaces only in the embedded clause.

Haddad suggests that in forward and backward raising, the subject first undergoes merge in the subordinate clause before it moves to the matrix clause. The difference, however, between the two structures lies in which copy is saved: if it is the copy of the matrix clause then it is a forward raising (5a); if it is the copy of the embedded clause, then it is a backward raising (5b).
a. [TP țafiq-a
n-na:s- $\mathrm{u}_{\mathrm{i}}$
started-3MS
the-people-NOM
[TP ja-nșarif-u:-n $\quad \mathbf{t}_{\mathbf{i}}$ ]]
'The people started to leave.'
b. [TP ka:d-at $\quad \mathbf{t}_{\mathbf{i}}$ [TP ta-tawaqqaf-u [NP harakat-u
1-sajja:ra:t] $\left.]_{i}\right]$
was.about-3FS 3F-stop-S.IND the.movement-NOM the-cars
'The cars almost stopped moving.'

\section{Pronouncing the head or the foot of a chain}

This section will address two possibilities: spelling out the higher or lower copies. Economy considerations alone favor a single application of Spell-out since the derivation involves less computational steps and hence becomes less costly (Uriagereka 1999 and Nunes 2004). Here, three topics are discussed: Copying of the Non-Quantificational Material of Wh-phrases, imperatives and perfectives, and enclitic object pronouns.

\subsection{Copying of the non-quantificational material of Wh-phrases}

Standard Arabic moves wh-phrases to C. The whole wh-phrase including the nonquantificational material is moved (6a). Arabic dialects, such as Jordanian Arabic $(\mathrm{JA})$, also move it as in $(6 \mathrm{~b})^{2}$. However, the non-quantificational material can be left behind as shown in (6c):
a. [Kam sukkar-an] $_{i}$
$\int \operatorname{taraj}-\mathrm{t}\left[\mathrm{t}_{\mathrm{i}}\right]$
SA
How much sugar-ACC buy:PRF:3SM-2SM
b. [gaddei sukkar $]_{i}$ how much sugar
Jtar-eit $\left[\mathrm{t}_{\mathrm{i}}\right]$ buy:PRF-2SM
c. ${\text { gaddei } \int_{\mathrm{i}} \quad \text { Jtar-eit }}$ [ $t_{i}$ sukkar] how much buy:PRF-2SM sugar
'How much sugar did you buy?'

The strong wh-feature of the interrogative complementizer can be checked by either the wh-word where the reduction of a wh-chain may only move the quantificational material to $[\mathrm{spec} / \mathrm{CP}]$ as in $(6 \mathrm{c})$, or by the whole wh-phrase moving to $[\mathrm{spec} / \mathrm{CP}]$ as in $(6 \mathrm{~b})$. In terms of economy, (6b) should be blocked given the fact that movement of the wh-word alone would suffice to check the strong wh-feature as illustrated in (6c). Put differently, according to the preference principle "Try to minimize the restriction in the operator position" (Hornstein et al. 2010:265), (6c) would be favored over (6b) since the non-quantificational material is deleted in the operator position.

In both sentences, the interrogative complementizer Q has a strong whfeature that must be overtly checked, otherwise the derivation will crash at PF. 
Therefore, when the formal features of gaddeif 'how much' move overtly to adjoin to Q, a feature checking will be established and thus the relevant uninterpretable wh-features get deleted. The difference between the two sentences then lies in covert versus overt movement. In (6b), movement is operating with a syntactic object: the phrase 'gaddeif sukkar how much sugar' is the smallest syntactic object that can allow the strong wh-feature of $\mathrm{Q}$ to be appropriately checked. In (6c), sukkar 'sugar' covertly moves where there is no need for piedpiping. The covert movement would be the optimal form and should involve only sets of formal features. Only formal features are moved. The wh-word moves leaving a copy of itself in the object position along with the non-quantificational material. However, in (6c), there is an overt movement of sukkar 'sugar' leaving behind a copy of the whole wh-phrase in the base-generated object position. The movement here represents a movement of categories rather than a movement of formal features. The strong wh-feature can only be checked by lexical items or projections of lexical items. Hornstein et al. (2010:312) maintain that economy considers moving (copying) less material better than moving more material. In other words, feature movement is preferred over category movement.

In terms of the copy theory, the difference between the sentences in (6) lies in which copy is spelled out and which one is silent. In (6c) the wh-word is pronounced in the head of the chain, while the non-quantificational element is pronounced in the foot of the chain by PLC and the copy in the head of the chain is silent. By contrast, in (6b) the wh-phrase, including the non-quantificational element, is pronounced in the head position, with lower members deleted at PF.

\subsection{Imperatives and perfectives in Arabic and PLC}

This section shows how the copy theory helps account for the morphological and syntactic differences between Arabic imperfectives on one hand, and perfectives and imperatives on the other. Specifically, it will be shown that the difference between them lies in pronouncing the higher or lower copy of the subject clitic along with the phi-features.

Imperative in Arabic has different forms that are used to instruct a second person depending on person - singular, dual or plural — and on gender masculine or feminine. The perfective forms are used to indicate events in the past regardless of their relevance to the present time. These forms are different from the imperfective forms since they have their own patterns/ meters and case markers. The imperfective has six different uses and thus is considered the unmarked form (Aoun, Benmamoun, \& Choueiri 2010) ${ }^{3}$.

Arab traditional grammarians considered the imperative as a third category of verbs due to having its own pattern and forms and expressing the future tense ${ }^{4}$. Compare the three verb forms in Arabic:

(7) a. faYal-a do:PRF:3SM-SUBJ

'He did.'

b. ya-f̧al-u 


\author{
IMPF:3SM-do-IND \\ 'He does/ he is doing.' \\ c. PI-fYal- $\varnothing$ \\ IMPR:2SM-do-JUSS \\ 'Do!'
}

In reference to the copy theory, Arabic imperatives and perfectives provide evidence for PLC ${ }^{5}$. Arabic, like many languages, shows a ban on negative imperatives (8b). Rather than using an imperative verb form, Arabic uses an imperfective jussive in the context under question, as illustrated in (8c). Arabic also disallows negative subjunctive perfective verbs, as shown in (8e). Instead, Arabic switches to jussive imperfective (8f), where tense is realized on the sentential negative marker lam: ${ }^{6}$

(8) a. Pu-ktub!

Write:IMPR:2SM:JUSS

'Write!'
b. *la: Pu-ktub!
Neg write:IMPR:2SM:JUSS
'Don't write!'
c. la: ta-ktub!
NEG IMPF:2SM-write:JUSS
'Don't write!'
d. al-bana:t-u katab-na d-dars-a
the-girls-NOM write: PRF-3PLF the-lesson-ACC
'The girls wrote the lesson.'
e. *al-bana:t-u la: katab-na d-dars-a the-girls-NOM NEG write: PRF-3PLF the-lesson
f. al-bana:t-u lam ja-ktub-na- $\varnothing$ d-dars-a
the-girls-NOM NEG:PST IMPF:3-write-PLF-JUSS the-lesson-ACC
'The girls did not write the lesson.'

Conceptually, we have the same pattern in both cases. Both disallow particular verbal forms to co-occur with negation, hence switching to another verbal form in the negative context. ${ }^{7}$

To account for the difference between the imperative and perfective forms on one hand and their negative counterparts on the other, let's consider the perfective and imperfective conjugation in Arabic. First, in the perfective paradigm, all $\phi$-features are realized by a suffix. By contrast, in imperfective forms person is mainly realized by a prefix, which also serves as the IMPF marker, and number and gender are realized by a suffix:

(9) a. zalasa-t-a:

sit:PRF-F-3,DUAL

'They (dual feminine) sat.'

b. ta-dzlis-a:n

IMPF:2-sit-DUAL,F

'You (both) sit.' 
Now, we get back to the derivation of (8d), the verb katabna 'they (F) wrote' merges with its NP complement $d$-darsa 'the lesson' and assigns accusative case to it. The VP merges with a light affixal verb, which triggers verb raising to $v$ to adjoin to the affixal $v$. The v-bar katabna $d$-darsa then merges with the external argument NP al-bana:t-u in [spec/vP]: (10)

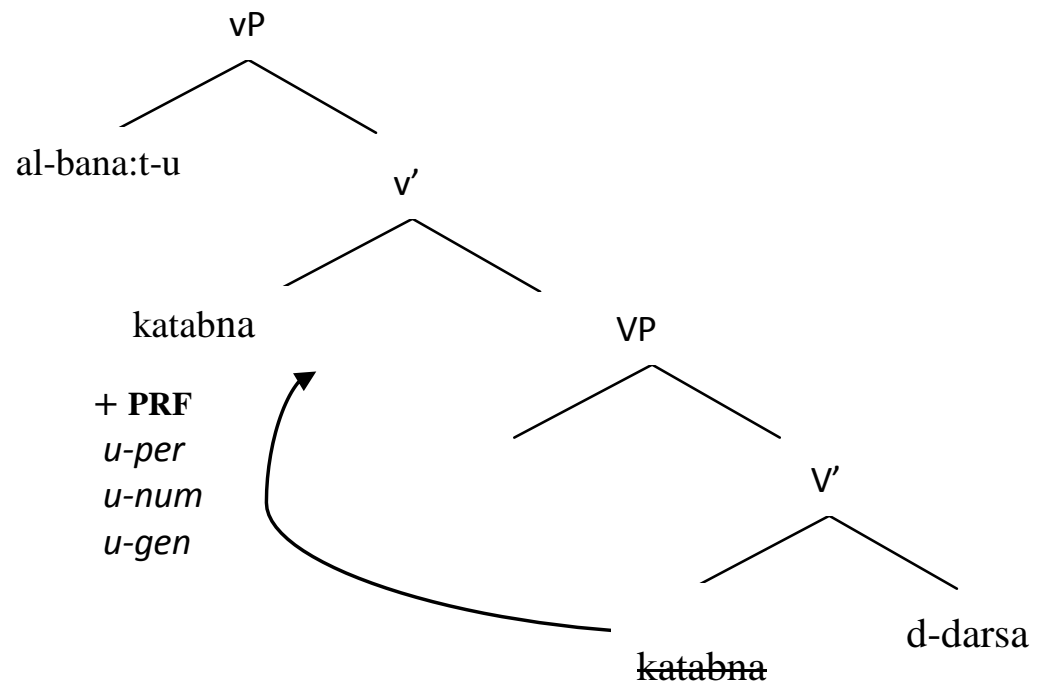

The whole vP then merges with an Asp head that has discontinuous $\phi-$ features as well as a [ $\pm \mathrm{IMPF}]$ feature, hence attracting katabna to adjoin to it. As a consequence, the subject NP al-bana:t- $u$ 'the girls' moves to [spec/Asp]. The derivation proceeds by $v$ raising to $\mathrm{T}$ with all $\phi$-features appearing as a suffix on the verb. The subject NP al-bana:t is still an active goal because of its $u$-case. According to Chomsky $(1995,2000)$, the NOM case of the subject is checked against a $\mathrm{T}$ head. Since $\mathrm{T}$ has a strong tense and EPP features, it triggers NP raising. Therefore, al-bana:t moves to [spec/TP]. As a probe, it gets its $u$-case checked and deleted against $\mathrm{T}^{0}$ that, in turn, gets the phi-features checked and deleted.

When the verb moves to $\mathrm{T}$, the pronominal subject suffix follows the verb in $\mathrm{T}$. This indicates that the only form of cliticization that the pronoun can undergo is encliticization (Aoun et al. 2010: 28-29).

Barjashtaser (1929) states that Arabic used to have only the NEG marker, $l a$, which was used with all verb forms. Later, it developed into other forms for specific purposes: namely, one for the past, lam, and one for the future, lan. So, according to the syntactic theory, we can conclude that lam and lan can be analyzed as a merger of NEG and T. In addition, NEG markers in the southern Arabic orthographies were only Pal, which means $l a$, that could be used with present and past and lam which was followed by imperfective form but rarely used (Ali 1957:179). 


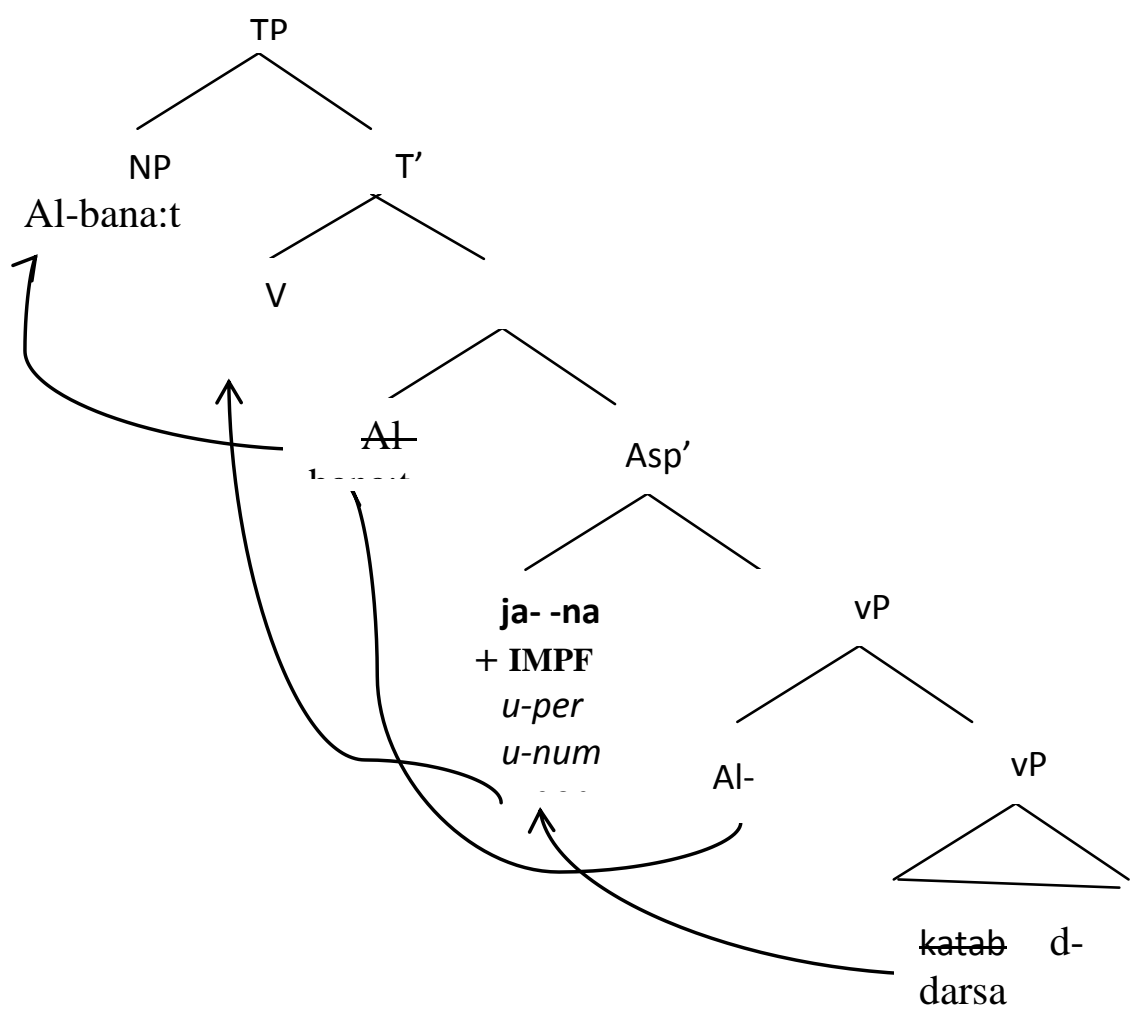

Let's now consider the derivation of the negative sentence in (8f). Here, NEG is followed by imperfective, which has a prefix representing person and IMPF and a suffix representing gender and number. To account for the appearance of tense on NEG in past sentences, let's assume that NEG is projected between $v$ and $\mathrm{T}^{8}$. The derivation starts with the verb merging with its internal argument complement and assigning accusative case to it. Then, the V' merges with a little verb which is affixal in nature, thus triggering verb to adjoin to $v$. Within the Chomsky (1993) framework, the v' then merges with the external argument, albana:t, that has $u$-case but interpretable person, number and gender features.

The vP then merges with a discontinuous affixal Asp head. Thus, it triggers verb movement to adjoin to it. The verb obtains person and IMPF prefix and number and gender suffix, hence appearing as yaktubna. The Asp head has also uninterpretable $\phi$-features. Therefore, it triggers the NP al-bana:t to move to [spec/Asp].

NEG is introduced in the derivation below T, specifically between AspP and TP. Then, it merges with $\mathrm{T}$ and the complex is realized morphologically as lam. Since NEG is generated between AspP and TP (Benmamoun 2000), it blocks the 
movement of the verb to $\mathrm{T}$. If the verb has moved to $\mathrm{T}$, it would have left behind the $\phi$-features, which, in turn, would all appear as a suffix. However, because the verb did not move to $\mathrm{T}$, the person feature, which represents a subject pronoun, will appear as a prefix and the number and gender features will appear as a suffix. Put differently, blocking the verb from moving to $\mathrm{T}$ forces it to appear without the past tense, hence appearing in the unmarked imperfective form with the person and IMPF affix procliticized. The subject NP al-bana:t needs to get its case assigned. As a result, it moves to [spec/TP]. There, it can probe and get its $u$-case checked against $\mathrm{T}^{0}$ and then deleted.

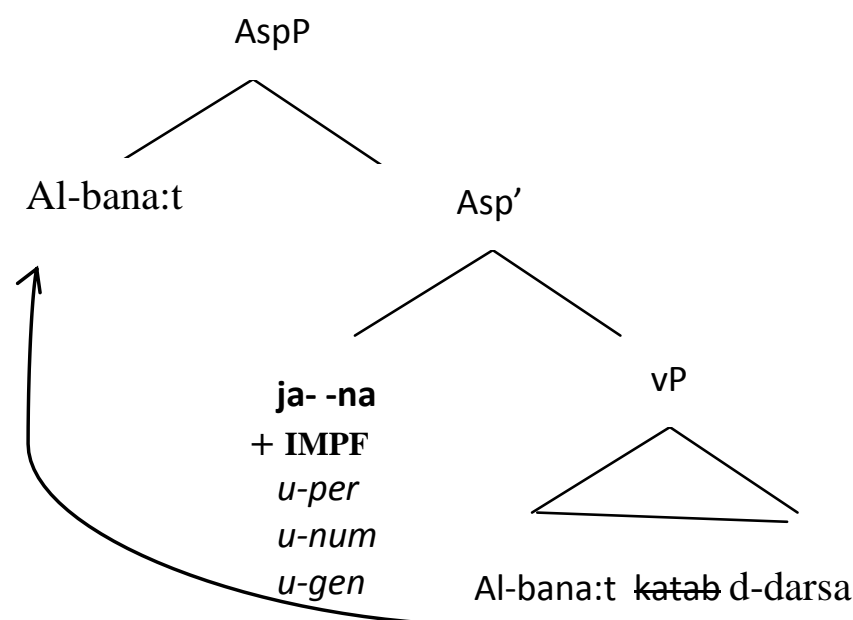

If this analysis is on the right track, we would expect perfectives to appear as imperfectives when they cannot move up to $\mathrm{T}^{0}$, for instance, when $\mathrm{T}^{0}$ is filled with an overt tense head. In fact, this is exactly what happens when kaan 'be', the past tense head, appears in $\mathrm{T}^{0}$ :
a. al-bana:t-u
katab-na
d-dars-a
the-girls-NOM
write:3PLF:PRF-SUBJ
the-lesson-acc
'The girls wrote the lesson.'
b. al-bana:t-u kun-na ja-ktub-na d-dars-a the-girls-NOM be:PST-3PLF IMPF:3-write-PLF the-lesson-ACC 'The girls were writing the lesson.'

In (13a) the verb could move up to $\mathrm{T}^{0}$ leaving behind all phi-features, hence appearing in the perfective form. By contrast, since $\mathrm{T}^{0}$ in (13b) is already filled with kunna 'be:PST-3PLF', the verb is forced to raise as high as AspP, thus person appears a prefix and number and gender as suffix.

The crux of the analysis is that the perfective (and the imperative) cannot co-occur with negation in Arabic because the co-occurrence results in a violation of the Stranded Affix Filter. Whereas Arabic person affixes generally precede the 
imperfective verb (14a), they follow it in perfective and imperative verbs, as exemplified in (14b\&c).

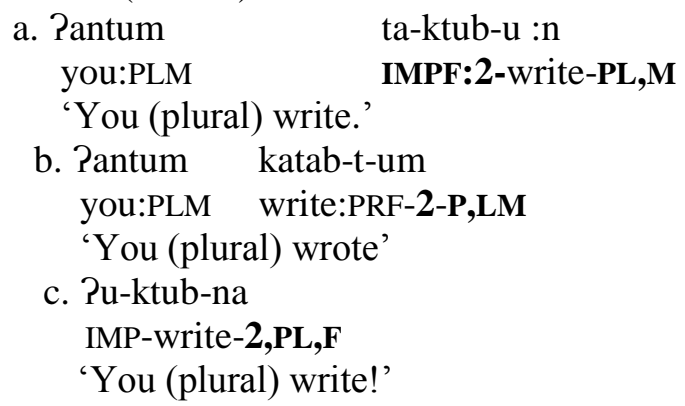

Now, we can propose a uniform account of (8f) and (14b\&c) based on the PLC mechanism. In Arabic the imperative and perfective forms and the imperfective form do not differ with respect to person affix placement in syntax. They both have the person-affix-V order, with a lower person copy of the affix following the verb. In imperfective forms, the higher copy of the clitic is pronounced. In imperative and perfective forms, pronunciation of the higher copy of the clitic leads to a Stranded Affix Filter violation, hence resulting in a PF violation. The violation can be avoided if we pronounce a lower copy of the affix, which follows the verb, as sketched in (15).

$$
\begin{aligned}
& \text { a. } \mathbf{t}-\mathrm{katab}-\mathbf{t}-\mathrm{i} \\
& \text { PER-write:PRF-PER-SF } \\
& \text { 'You (SF) wrote.' } \\
& \text { b. lam } \quad t-k t u b-\mathbf{t}-\mathbf{i} \\
& \text { NEG:PAST PER-write:prf-PER-SF } \\
& \text { 'You (SF) did not write.' }
\end{aligned}
$$

In sum, in the perfective form, merger takes place between the verb and the person lower copy in order to avoid a PF violation as in (15a). Whereas in the imperfective form, the PF merger takes place between the verb and the person upper copy as in (15b).

\subsection{Enclitic object pronouns}

Although Arabic has free word order, it is sometimes mandatory to have a certain word order. Here, we will discuss the VOS order and show how the copy theory accounts for this word order, which is marked in the language.

As a matter of fact, VOS is the order that must be used with the attached (enclitic) ACC object pronouns as (16a). Compare the VOS here to the canonical SVO and VSO word orders when the object is an R-expression (17a\&b):

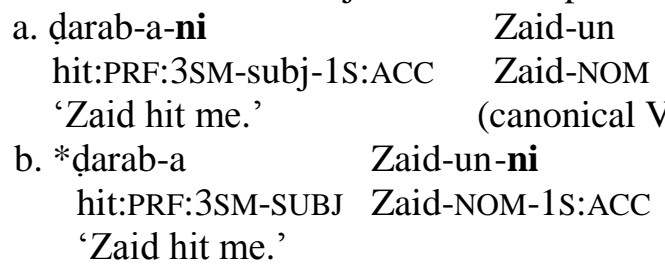
a. Zaid-un darab-a
Amr-an (canonical SVO order) 


\begin{tabular}{lll}
\multicolumn{2}{l}{ Zaid-NOM hit:PRF:3SM-SUBJ } & Amr:ACC \\
$\begin{array}{c}\text { 'Zaid hit Amr.' } \\
\text { b. darab-a }\end{array}$ & Zaid-un & Amr-an (canonical VSO order) \\
hit:PRF:3SM-subj & Zaid-NOM & Amr:ACC \\
'Zaid hit Amr.' & & \\
$\begin{array}{c}\text { c. darab-a } \\
\text { hit:PRF:3SM-subj }\end{array}$ & Amr-an & Aaid-un (focalized VOS order) \\
'Zaid hit Amr.' & & Zaid-NOM
\end{tabular}

Sentence (16a) has a VOS order, and so it is expected to have a marked word order as in (17c). However, since the object is realized as an attached (enclitic) ACC pronoun, the best way to derive the sentence is to follow the VOS order in accordance with Stranded Affix Filter. By contrast, when the object is an R-expression, the SVO and VSO word orders sound natural (17a\&b) and the VOS order sounds unnatural and would only be acceptable if the object was focalized $(17 \mathrm{c})$.

Thus, we assume that the VOS order in (16a) must be related either to the SVO in (17a) or to the VSO in (17b). To solve this issue, we need to consider the two word orders in Arabic. The SVO and VSO orders are semantically different ${ }^{9}$. This indicates that VSO and SVO are not derived from each other. Put differently, the SVO-VSO word order alternation in SA is not due to the presence versus absence of subject movement to [Spec/TP]; instead it is a consequence of two different base-generated structural representations.

Now let's get back to our question: is the marked VOS order in (16a) derived from the SVO in (17a) or from the VSO in (17b)? Given the semantic difference between the two word orders, it seems that it is derived from VSO order since the incident is reported in a neutral way. In addition, as mentioned before, the postverbal subject is not in a focalized position. If the subject and/or the object were focalized, they would appear preverbally and we would end up having either SVO, SOV, or OVS word orders.

In terms of the copy theory, the derivation starts by merging the lexical verb Daraba 'hit' with its object pronominal complement $-n i$ 'me'. Then, the verb moves to attach to a null affixal light verb in $v$. The resulting $v$ ' merges with the external argument Zaid.

The derivation proceeds by verb movement to $\mathrm{T}$ in order to check the uninterpretable person, number and gender features of $\mathrm{T}$. However, since the object is an attached (enclitic) pronoun, it cannot be stranded in situ due to the Stranded Affix Filter. So, it is pied-piped along with the verb leaving a copy in its base-generated position as shown in the simplified structure in (19). 


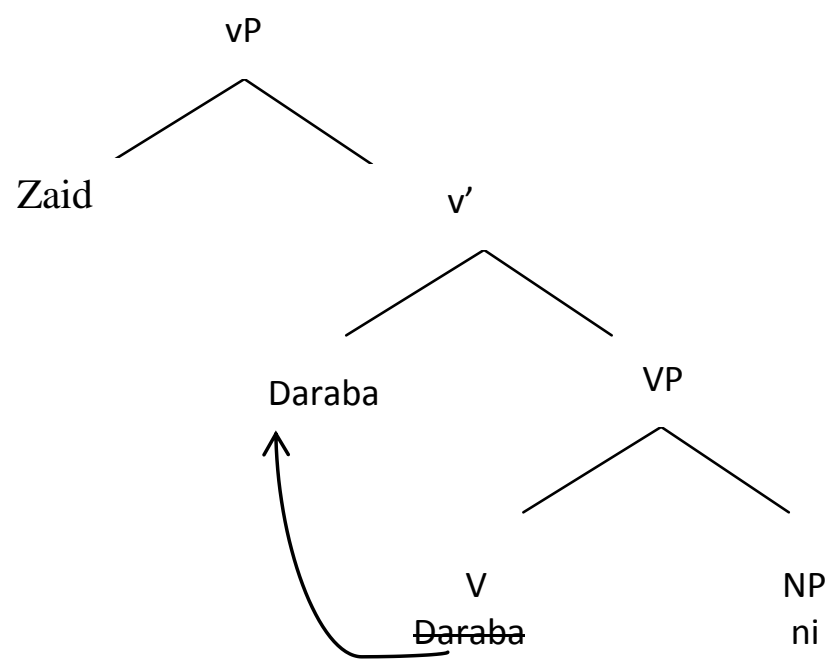

The derivation proceeds by verb movement to $\mathrm{T}$ in order to check the uninterpretable person, number and gender features of $\mathrm{T}$. However, since the object is an attached (enclitic) pronoun, it cannot be stranded in situ due to the Stranded Affix Filter. So, it is pied-piped along with the verb leaving a copy in its base-generated position as shown in the simplified structure in (19).

[те T Darana-ni [vP [NP Zaid [v' Daraba [vP V Daraba [NP - ni]]]]]]

This indicates that in VSO orders, there are two options for the spellout of the NP object: when it is an R-expression, the lower- in situ- copy is pronounced, whereas when it is a pronoun, the upper copy is pronounced. The NP object is a goal since it has a $u$-case. This feature must be checked and valued by a local probe, the lexical verb. When the verb moves to a higher functional head like $\mathrm{Asp}^{0}$ or $\mathrm{T}^{0}$, it assigns, and thus checks, the accusative case of the object pronominal NP which, in turn, checks the uninterpretable features of the verb. Since they are affixal, pronominal NPs are in need for a potential host. The best candidate here is the lexical verb because it is a case assigner of the object NP. In doing so, the distance between the probe and the goal becomes minimal since the object NP complement is adjacent to the verb.

\section{Conclusion}

This paper discussed copying in Standard Arabic. It was shown that Arabic may pronounce the upper or lower copy without causing the derivation to crash. In examining wh-copying, it was shown that the wh-word may be pronounced in the head of the chain, while the non-quantificational element is pronounced in the foot of the chain by PLC or the wh-phrase and the non-quantificational element may both be pronounced in the head position with lower members deleted at PF. Based on evidence of blocking V-to-T movement when $\mathrm{Neg}^{0}$ intervenes, imperatives and perfectives lent evidence that Arabic pronounces the PERSON feature in the foot of the chain whereas imperfectives pronounce the PERSON 
feature in the head of the chain. Finally, the copy theory helped account for the non-canonical VOS orders when the object is not focalized. 


\section{Endnotes}

${ }^{1}$ This topic will be discussed in section 3.1

${ }^{2}$ Egyptian Arabic leaves wh-word in-situ.

${ }^{3}$ The default mood for Arabic verbs is as follows: indicative for imperfective, subjunctive for perfective, and jussive for imperative.

${ }^{4}$ Unlike imperfective verbs, the imperative and the perfective are "built" verbs, which mean that they retain the same case marking and do not undergo any inflectional change if they happen to follow certain functional elements like negation. However, the imperfective can appear in the subjunctive mood, if, for example, it is preceded by a complementizer; or in the jussive mood if preceded by the conditional PIn 'if'. Example (i) expresses an imperfective in the subjunctive mood, and (ii) an example in the jussive:
i. qarrar-tu Pan Pa-staqi:l-a

decide:PRF-1S COMP IMPF:1S-resign-SUBJ

'I decided to resign'
ii. PIn ta-ðhab- $\varnothing$ Рa-ðhab- $\varnothing$
If IMPF:2S-go-JUSS IMPF:1S-go-JUSS
'If you go, I will go'

${ }^{5}$ Greek Imperatives also lend some evidence for PLC as discussed in Miyoshi (2002) and Boskovic and Nunes (2007).

${ }^{6}$ The tense also appears on the future negative marker lan:

i. Sa-ya-ktub-u

FUT-IMPF:3SM-write-IND

ii. Lan ya-ktub-a

NEG:FUT IMPF:3SM-write-SUBJ

${ }^{7}$ Similar cases exist in other languages. For instances, Miyoshi (2002) provides a uniform account of the ban on negative imperatives in Greek and the ban on negative indicatives in English.

${ }^{8}$ See Aoun, Choueiri and Benmamoun (2010) for similar analysis of projecting NEG between $\mathrm{V}$ and $\mathrm{T}$.

${ }^{9}$ There are other differences in syntax and CASE properties.

Ayman Yasin $(\mathrm{PhD})$

Princess Sumaya University for Technology

Amman-Jordan

Email: aymanolu@gmail.com 


\section{References}

Ali, Jafar. (1957). Tarikh Al-Arab qabla l-Islam [Arab Pre-Islam History] Baghdad: Matba't al-majma' al-'Imi Al-iraqi.

Aoun, Joseph, Elabbass Benmamoun, \& Lina Choueiri. (2010). Arabic Syntax. Cambridge: Cambridge University Press.

Barjashtaser (1929). Al-TaTawwur Al-Nahawi li-Lughati Al-'Arabiyya [The Syntactic Evolution of Arabic]. Egypt: Matba't Al-Samah.

Benmamoun, Elabbass. (2000). The Feature Structure of Functional Categories: A Comparative Study of Arabic Dialects. Oxford: Oxford University Press.

Bobaljik, Jonathan. (1995). Morphosyntax: The Syntax of Verbal Inflection. Doctoral Dissertation, Cambridge: MIT Press.

Bobaljik, Jonathan. (2002). 'A-chains at the PF-interface: copies and covert movement'. Natural Language and Linguistic Theory 20 (2). 197-267.

Boskovic, Zeljko and Jairo Nunes. (2007). 'The copy theory of movement: A view from PF'. In Norbert Corver, \& Jairo Nunes (eds.), The Copy Theory of Movement, 13-74. Amsterdam: John Benjamins.

Brody, Michael. (1995). Lexico-Logical Form: A Radically Minimalist Theory. Cambridge: MIT Press.

Chomsky, Naom. (1993). 'A minimalist program for linguistic theory'. In Kenneth Hale and Samuel Keyser (eds.), The Minimalist Program, 167217. Cambridge: MIT Press.

Chomsky, Naom. (1995). The Minimalist Program. Cambridge: MIT Press. Vol. 1765.

Chomsky, Naom. (2000). 'Minimalist inquiries: The framework'. In Martin, Roger, David Michaels \& Juan Uriagereka (eds.) Step by Step: Essays on Minimalist Syntax in Honor of Howard Lasnik, 89-155. Cambridge: MIT Press.

Franks, Steven. (1998). 'Clitics in Slavic. Paper presented at the Comparative Slavic Morphosyntax Workshop. Indiana Spencer Creek.

Haddad, Yousef. (2012). Raising in Standard Arabic: Forward, backward, and none. In Reem Bassiouney \& Graham Katz (eds.), Arabic Language and Linguistics, Washington, DC: Georgetown University Press.

Haegeman, Lilianne. (2009). Thinking Syntactically: A Guide to Argumentation and Analysis. John Wiley \& Sons.

Hiramatsu, Kazuko. (2000). Accessing Linguistic Competence: Evidence from Children's and Adults Acceptability Judgments. Doctoral dissertation, University of Connecticut: Storrs, CT, USA.

Hornstein, Norbert, Jairo Nunes \& Kleanthes Grohmann. (2010). Understanding Minimalism. Cambridge: Cambridge University Press.

Lambova, Mariana. (2002). 'On A'-Movements in Bulgarian and their interaction'. The Linguistic Review 18:327-374. 
Lambova, Mariana. (2004). On Information Structure and Clausal Architecture: Evidence from Bulgarian. Doctoral dissertation. University of Connecticut: Storrs, CT, USA.

Landau, Idan. (2003). Modular Recoverability: Chain Resolution in Hebrew VPFronting. Manuscript, Beer-Sheva, Israel.

Miyoshi, Nobuhiro. (2002). Negative Imperatives and PF Merger. Manuscript, University of Connecticut: Storrs, CT, USA

Nunes, Jairo. (1995). The Copy Theory of Movement and Linearization of Chains in the Minimalist Program. Doctoral dissertation, University of Maryland, College Park. MD, USA.

Nunes, Jairo. (2001). 'Sideward movement'. Linguistic Inquiry, 32(2), 303-344.

Nunes, Jairo. (2004). 'Linearization of chains and sideward movement'. Linguistic Inquiry Monographs 43. MIT Press.

Pesetsky, David. (1997). 'Optimality theory and syntax: Movement and pronunciation'. In Diana Archangeli \& Donald Terence Langendoen (eds.) Optimality Theory: An Overview, 134- 170. Malden: Blackwell.

Pesetsky, David. (1998). 'Some optimality principles of sentence pronunciation'. In Barbosa Fox, Paul Hagstrom, Martha McGinnis, and David Pesetsky (eds.), Is the Best Good Enough, 337-383. Cambridge: MIT Press and MIT WPL.

Radford, Andrew. (2009). An Introduction to English Sentence Structure. Cambridge: Cambridge University Press.

Roberts, Ian. (1997). 'Restructuring, head movement, and locality'. Linguistic Inquiry 28: 423-460.

Runner, Jeffrey. (2013). Noun Phrase Licensing. Oxfordshire: Routledge.

Uriagereka, Juan. (1999). 'Multiple spell-out'. In Samuel David Epstein and Norbert Hornstein (eds.), Working Minimalism, 251-282. MIT Press. Mass, USA. 